\title{
The impact of motor competence on energy expenditure during object control skill performance in children and young adults
}

\author{
RYAN S. SACKO ${ }^{1}$ | TLLL UTESCH'2 | FARID BARDID3,4 | DAVID F. STODDEN 5 \\ 1 The Citadel, Department of Health and Human Performance, South Carolina, United States of America. \\ 2 University of Müenster, Münster, Germany. \\ 3 University of Strathclyde, School of Education, Glasgow, United Kingdom. \\ ${ }^{4}$ Ghent University, Department of Movement and Sports Sciences, Ghent, Belgium. \\ ${ }^{5}$ Department of Physical Education, University of South Carolina, South Carolina, United States of America.
}

Correspondence to: Ryan S. Sacko, +1(803) 447-2367, twitter: ryansacko, orcid.org/0000-0002-2104-6265.

email: rsacko@citadel.edu

https://doi.org/10.20338/bjmb.v15i2.208

\author{
HIGHLIGHTS \\ - This study uses RSAs to illustrate the effects \\ of skill level on energy expenditure. \\ - First study to explore the impact of skill and EE \\ levels during ball skills. \\ - Provides evidence that the repetitive practice \\ of object control skills can aid in the \\ accumulation of recommended levels of EE.

$\begin{array}{ll}\text { ABBREVIATIONS } \\ \text { AIC } & \text { Akaike information criterion } \\ \text { Adjusted } & R^{2} \text { Explained variance } \\ b_{0} & \text { Intercept } \\ b_{1} \text { to } b_{5} & \text { Regression coefficients in the RSA } \\ \text { CFI } & \text { Comparative fit indices } \\ \text { EE } & \text { Energy expenditure } \\ \text { MC } & \text { Motor competence } \\ \text { ML } & \text { Maximum likelihood estimator } \\ \text { METS } & \text { Metabolic equivalence of task } \\ \text { p } & \text { Absolute significance of the model } \\ \text { PA } & \text { Physical activity } \\ \text { RSA } & \text { Response surface analysis }\end{array}$

PUBLICATION DATA

Received 19102020

Accepted 11122020

Published 01062021
BACKGROUND: An understanding of how motor skill performance levels relate to energy expenditure $(E E)$ is an important, yet relatively unexplored topic that may better inform physical activity interventions.

AIM: This study examined the impact of motor competence (MC) on EE during the performance of object control skills in children and young adults.

METHOD: Forty-two children (Mage 8.1 years) and 40 young adults (Mage $=23.4$ years) completed sessions of throwing and kicking at varying intensity intervals. Polynomial regressions with response surface analysis were conducted to analyze the impact of process- and product-oriented MC levels on EE.

RESULTS: Moderate positive associations among process-oriented motor competence levels and EE were demonstrated in all trial interval conditions with stronger associations shown for shorter trial intervals.

CONCLUSION: Individuals' movement quality (process) demonstrated greater associations with EE than performance product (speed), especially with higher intensity skill practice. These results provide additional evidence of the positive impact that MC has on the health benefits of physical activity, specifically during participation in activities that inherently require repeated performance of object control skills.

KEYWORDS: Product-oriented | Process-oriented | Motor skills | Measurement | Physical activity | Response surface analysis

\section{INTRODUCTION}

Childhood is a critical time for the development of competence in a variety of gross motor skills as they are the building blocks for more complex movements that are demonstrated in a variety of activities across the lifespan. ${ }^{1} \mathrm{~A}$ large and constantly growing literature base continues to support the impact that motor competence (MC) has on healthrelated outcomes (i.e., physical activity, fitness, and body weight status). ${ }^{2}$ Recent evidence demonstrates that repeated performance of various motor skills at different intensities is associated with moderate to high energy expenditure (EE) levels. ${ }^{3-5}$ However, research examining the impact that competence levels have on EE is lacking. It is important to understand how differences in competence levels relate to both acute as well as long-term 
EE levels as it may influence how interventions are structured to maximize the health benefits of physical activity (PA).

Motor skills are generally separated into three broad categories: locomotor (e.g., walk, run, hop), balance/stability (e.g., bend, twist), and object control skills (e.g., throw, kick, strike). Performing activities that involve continuous locomotor skills such as walking or running and participating in activities like soccer or tennis have been recommended to achieve health-enhancing levels of $\mathrm{PA}^{6}$ in both children and adults. ${ }^{7,8} \mathrm{EE}$ levels assessed during these activities generally is high 9,10 ; however, an understanding of how the performance of object control skills (e.g., kicking, throwing, and striking) contributes to EE during activities that inherently involve these skills when integrated in gameplay or during specific practice has only recently been investigated. ${ }^{3-5}$ Recently, Sacko et al. (2018 \& 2019) explored the EE of object control skills in children and young adults. Results from Sacko et al. (2018 \& 2019) demonstrated that the repetitive performance of object control skills at intervals of 6,12 , and 30 seconds resulted in moderate to vigorous PA regardless of the performers' skill level.,3 Thus, if the repetitive performance of object control skills is associated with high $\mathrm{EE}$, then promoting their development during PA interventions and physical education will have both an acute and long-term health-enhancing benefit.2,11-13 The relationship between $\mathrm{EE}$ and object control skill performance is important as the practice of these skills in a variety of settings (e.g., playing catch, gameplay, physical education, sport practice) generally involves multiple repetitions, but at varied intervals (i.e., variable trials/minute). Thus, it is important to understand how the number of trials performed per unit of time in an activity impact EE.

The performance of object control skills involves complex multi-joint movements that demand high neuromuscular involvement due to the activation of large muscle groups when produced with high effort. ${ }^{3-5,11,12}$ Neuromuscular demands associated with object control skills are substantially higher than locomotor skills of moderate intensity (e.g., jogging) suggesting that EE would also be high when these type of skills are repeated in a play or practice context. ${ }^{14-16}$ Furthermore, a noted increase in the number of degrees of freedom utilized during movement occurs as object control skill level of a performer increases, necessitating greater neuromuscular involvement and intensity (i.e., increased joint range of motion, muscle recruitment, and muscle activation with increased force production), specifically when performing at high effort levels. ${ }^{16-19}$ The increased neuromuscular demand presumably increases metabolic energy demand. Contrasting this view is the notion that a higher level of skill is associated with increased efficiency of movement. ${ }^{20}$ Thus, when comparing the performance of a skill between a less skilled and a highly skilled performer, it is generally assumed that the higher skilled performer would be more efficient (i.e., lower EE) in their performance. ${ }^{20}$ However, this assumption has not been empirically tested. Additionally, this assumption would rely on an additional assumption that the output of both performers would be fixed (i.e., the same performance outcome), which does not take into account the neuromuscular demand and resultant EE with high effort performance. As effortful practice is a fundamental requirement for advancing skill levels, specifically with object control skills such as kicking, throwing, and striking, understanding differences in EE between higher and lower-skilled individuals during a performance would generally be associated with high effort performance, regardless of skill level. ${ }^{14,18,21-25}$ 
Updated recommendations from the Physical Activity Guidelines Advisory Committee (2018) highlight the need to a) increase our understanding of dose-response relationships between PA and multiple health outcomes throughout the lifespan, and b) develop instrumentation and measurement techniques that will enhance PA surveillance systems. ${ }^{6}$ Examining MC includes the evaluation of both the process- and product-oriented assessments of a wide range of skills. ${ }^{26} \mathrm{An}$ initial step in understanding the dose-response relationships between different types of PA (e.g., skill practice and performance) and health outcomes is to explore the interactions of skill performance respective to process- and product-oriented assessments. One type of process-oriented skill assessment that relies on the qualitative interpretation of movement performances respective to independent components (i.e., body segments or limbs) known as developmental sequences. ${ }^{27}$ Qualitatively different component levels are evaluated on an ordinal scale with higher levels representing a more skillful performance. Although process-oriented skill assessments provide specific descriptions of performers' actions during a skilled event, each component must be analyzed independently, a process that requires high levels of experience and large quantities of time to interpret. In contrast, a product-oriented assessment provides instantaneous results of the outcome of a movement, albeit through the use of tools (i.e., radar gun) that may be expensive and difficult to obtain by the end user. Product-oriented assessments provide data in the form of a quantitative score (e.g., speed, force, or the number of successful attempts). ${ }^{28}$ Intuitively, one would expect that a strong relationship exists between process- and product-oriented motor skill measurements; however, this alignment has yet to be established in children. Recent studies have reported low (5.3\%; 4-11 year olds ${ }^{29}$ ) to moderate amounts of variance explained (27\%; 5-8 year olds ${ }^{30}$ ) between overall performance on the process-oriented TGMD-2 and the product-oriented Movement Assessment Battery for Children-2 ${ }^{\text {nd }}$ edition.29,30 However, unlike the aforementioned studies where product and process measures were dissimilar, the strength of association grows when the measurement of product and process-oriented measure occurs within the same motor skill assessment. For example, developmental sequence levels for throwing predict $69-85 \%$ of ball speed in children aged $6-13$ years. ${ }^{31}$

Exploring the EE of object control skill performance has the potential to improve our understanding of how different activities contribute to the metabolic outputs performed at varying levels of skills and their contribution toward health outcomes throughout the lifespan. A heightened understanding of the relationship between process- and product-oriented skill assessments may allow for the development of instrumentation and measurement techniques that will better inform PA surveillance systems. Thus, the purpose of this study was to determine relationships between process- and product-oriented MC performance levels and METS (metabolic equivalence of task) during object control skill performance in children and young adults.

\section{METHODS}

This study included data from two different projects that focused on EE during object skill performance. Both studies used identical methodologies and collection protocols that are described elsewhere (i.e., Sacko et al. 2018 \& 2019).,3,4 Data on 42 elementary school- 
aged (Mage 8.1 years) children and 40 young adults (Mage $=23.4$ years) were analyzed for this study. The studies were approved by the University Institutional Review Board and the ethical treatment of participants was followed. Young adults and parents of participating children provided consent and children provided assent. Children and young adults with physical disabilities or medical conditions that prevented them from completing testing were excluded from initial testing. Participants performed three nine-minute MC interval sessions where participants performed rounds of 5 kicks, 5 throws, and 5 strikes in blocked fashion, at three different trial intervals (i.e., where one kick, throw, or strike was performed every 6 , 12 , or 30 seconds). Each participant completed the three MC interval sessions in a randomized order. Participants were instructed to perform all trials with maximum effort. Each interval session was followed by a cool-down period in a seated position that lasted no less than 10 minutes to allow a return to resting state metabolism. ${ }^{32}$ The interval schedules ranged from more intense (i.e., 6 second intervals to less intense intervals (i.e., 30 second intervals) that could be expected in different practice, training, or physical education environments. EE was measured with a COSMED K4b2 portable gas analyzer (COSMED, Rome, Italy). This lightweight device collects expired respiratory gases on a breath-bybreath basis to measure oxygen consumption $\left(\mathrm{VO}_{2} ; \mathrm{ml}^{\mathrm{kg}} \mathrm{kg}^{-1} \cdot \mathrm{min}^{-1}\right)$ and compute the metabolic equivalent of task (MET). ${ }^{10}$ Activities that require at least 4 METS in children and at least 3 METS in adults are classified as moderate intensity activity in children, with $>7$ METS in children and $>6$ METS in young adults being classified as vigorous activities. ${ }^{7,8}$ The average of MET values between minutes 4-8 was computed for each bout. Prior to starting the skill performance bouts, $\mathrm{VO}_{2}$ was measured during rest to establish baseline MET values; these values were used for the cool-down period to ensure recovery to a resting state following each bout. The gas analyzer was calibrated with standard gases before each measurement occasion. ${ }^{10}$ The device was worn by the participants according to the product guidelines. ${ }^{15}$

\section{Process-Oriented Skill Assessment}

Skill performances of kicking and throwing were video-recorded during the 30 second interval condition and scored post-hoc using validated developmental sequences for the throwing.27,33 The developmental sequence levels were scored based on the coordination pattern that was observed for the different segmental components of kicking and throwing. The modal level from five trials of kicking and throwing were summed and used for data analysis. Prior to data reduction of the videos, three trained members of the research team categorized randomly-selected video recorded trials to establish inter-rater reliability. Inter-rater reliability was established using a Kappa statistic ${ }^{34}$ to determine the strength of agreement between these research team members which ranged from $k=.880$ - .960. Fourteen days after initial coding, each of the three research team members coded the same randomly-selected trials to establish intra-rater reliability. Intra-rater ranged from $k$ $=.900-.945$.

\section{Product-Oriented Skill Assessment}

Maximal ball speeds during kicking and throwing, were recorded during the 30 second trial by radar gun (STRIKER Inc. Plano, TX) to assess skill levels. ${ }^{31,35}$ Speeds were 
also recorded during pre-testing and intermittently during the 6 and 12 second trial intervals to ensure participant's consistent effort and performance level. Z-scores were computed for maximum kicking and throwing speed, and summed to obtain a composite score of object control competence.

\section{Data analysis}

Participant descriptive statistics were calculated for the total sample and by sex and reported as means (+/- SD) in Table 1.

First, the correlations between METS, product-oriented object control skill competence (i.e., speed) and process-oriented object control skill competence were calculated using bivariate Pearson correlation coefficients.

Second, multiple linear regressions, as well as second degree polynomial regressions with response surface analysis (RSA) ${ }^{36}$, were conducted in order to analyze the effects of process- and product-oriented object control skill competence on METS separately for children and young adults in the three conditions: 6 seconds, 12 seconds and 30 seconds. The RSA was used because it has several advantages compared to an ordinary least square multiple regression. ${ }^{36}$ While ordinal least square models compute regression effects for each variable in so-called 'full models', the RSA takes into account that statistical modeling should always aim at finding the best fitting and, at the same time, the most parsimonious model. ${ }^{37}$ This approach ensured avoiding over- and underfitting models by applying a maximum likelihood estimator that facilitated the analysis of the effects of different fit patterns of the two-predictor variables on the outcome variable using a path modeling approach. That is, several models with specific patterns between the different regression coefficients are estimated and compared to each other. Examples of these models include the null model, a model with only the linear main effect of the first predictor variable (only-x), the second predictor variable (only-y), another model with only the linear main effect,, and a model with both linear effects (additive; Schönbrodt, 2017). ${ }^{36}$ To identify the best and most parsimonious model and to avoid the selection of over- and underfitting models, the relative model fit between all estimated models were inspected using Akaike's Information Criteria ${ }^{37}$, because nested and non-nested models were compared. The Akaike information criterion (AIC) index adjusted the predictive accuracy of a model relative to its complexity (parsimony).

Model fit of the best fitting models were reported using an information criterion (AIC), an incremental measure (i.e., comparative fit indices; $C F I)$, the absolute significance of the model $(p)$, and explained variance (adjusted $R^{2}$ ). Outliers were controlled according to the criteria introduced by Bollen and Jackman (1985). ${ }^{38}$ The polynomial regression of the second degree was estimated using equation (1), while the multiple linear regression was estimated using equation (2):

$$
\begin{gathered}
\text { METS } \sim b_{0}+b_{1}{ }^{*} \text { process }+b_{2}{ }^{*} \text { product }+b_{3}{ }^{*} \text { process }{ }^{2}+b_{4}{ }^{*} \text { process }{ }^{*} \text { product }+ \\
b_{5} * \text { product }{ }^{2}
\end{gathered}
$$

$$
\text { METS } \sim b_{0}+b_{1}{ }^{*} \text { process }+b_{2}{ }^{*} \text { product }+b_{4} * \text { process * product }
$$


The intercept is $b_{0}$. Regression coefficients in the RSA are $b_{1}$ to $b_{5}$ are shown in their original scale and as standardized $\beta$ weights. The linear main effects $b_{1}$ (processoriented object control skill competence) and $b_{2}$ (product-oriented object control skill competence). The curvilinear main effects are $b_{3}$ (process-oriented object control skill competence) and $b_{5}$ (product-oriented object control skill competence), but they are not necessarily part of the most parsimonious model. The interaction effect is $b_{4}$ (processoriented object control skill competence * product-oriented object control skill competence). Both predictors (i.e., product-oriented object control skill competence, process-oriented object control skill competence) were z-transformed by sex in order to control for sex effects. In the RSA, values are estimated using the maximum likelihood estimator (ML) and robust standard errors, which are robust against violations of the assumption of normality.

Statistical analyses were executed using $R^{39}$ and primarily the $R S A$ package. ${ }^{36}$ Open code and data are provided in this study (osf.io/project-name).

\section{RESULTS}

In the first step, we investigated the correlations between METS, process- and product-oriented object control skill competence separately for children and young adults. All demographic information can be found in Table 1. Process- and product-oriented object control skill competence were positively associated with METS in the 6 second condition and in the 12 second condition for children and young adults. However, correlations were descriptively higher in young adults and there was an additional significant moderate correlation with the METS in the 30 second condition (see Table 2 for a detailed overview).

Table 1 - Descriptive Characteristics of Study Participants, Energy Expenditure (METS), and Speed (mph)

\begin{tabular}{|c|c|c|c|c|c|c|c|c|}
\hline & Age & $\frac{\text { Body mass }}{(\mathrm{kg})}$ & $\underline{\text { Height }(\mathrm{cm})}$ & $\frac{6 \text { second }}{\text { (METS) }}$ & $\frac{12 \text { second }}{\text { (METS) }}$ & $\frac{30 \text { second }}{\text { (METS) }}$ & Kick (mph) & $\frac{\text { Throw }}{(\mathrm{mph})}$ \\
\hline Adult Total & $23.4 \pm 2.6$ & $77.3 \pm 16.8$ & $171.4 \pm 7.3$ & $8.2 \pm 1.6$ & $\overline{5.7 \pm 1.2}$ & $3.5 \pm 0.7$ & $42.3 \pm 8.0$ & $52.3 \pm 15.6$ \\
\hline $\operatorname{Men}(n=20)$ & $23.3 \pm 2.9$ & $82.7 \pm 173$ & $175.8 \pm 5.5$ & $9.2 \pm 1.3$ & $6.2 \pm 1.2$ & $3.8 \pm 0.7$ & 6.0 & $65.2 \pm 8.5$ \\
\hline Women $(n=20)$ & $23.2 \pm 2.3$ & $72.0 \pm 14.4$ & $166.9 \pm 6.0$ & $7.3 \pm 1.4$ & $5.2 \pm 1.0$ & $3.2 \pm 0.4$ & 37.6 & $40.7 \pm 10.6$ \\
\hline Children Total & $8.1 \pm 0.8$ & $29.1 \pm 5.6$ & $134.4 \pm 7.6$ & $8.3 \pm 1.6$ & $6.3 \pm 1.3$ & $4.5 \pm 0.7$ & $27.8 \pm 7.6$ & $30.8 \pm 8.7$ \\
\hline Boys $(n=22)$ & $8.1 \pm 0.8$ & $33.2 \pm 4.3$ & $139.3 \pm 6.3$ & $9.3 \pm 1.3$ & $7.0 \pm 1.1$ & $4.8 \pm 0.7$ & $27.8 \pm 7.7$ & $30.7 \pm 8.9$ \\
\hline Girls $(n=20)$ & $8.1 \pm 0.8$ & $30 \pm 6.6$ & $135 \pm 8.8$ & $7.2 \pm 1.1$ & $5.6 \pm 1.1$ & $4.1 \pm 0.7$ & $28.3 \pm 8.3$ & $25.7 \pm 5.5$ \\
\hline
\end{tabular}

All measures presented as means \pm standard deviation; METS = Metabolic Equivalence of Task; $m p h=$ miles per hour 
Brazilian Journal of Motor Behavior

\section{Research Article}

Table 2 - Correlation matrix.

\begin{tabular}{|c|c|c|c|c|}
\hline & 1 & 2 & 3 & 4 \\
\hline \multicolumn{5}{|l|}{ Children } \\
\hline 1. Process-oriented object control skill & - & & & \\
\hline 2. Product-oriented object control skill & $.766^{\text {t*t+ }}$ & - & & \\
\hline 3. METS 6 seconds interval & $.441^{* *}$ & $.405^{* *}$ & - & \\
\hline 4. METS 12 seconds interval & $.358^{*}$ & $.311^{*}$ & $.874^{*+*}$ & - \\
\hline 5. METS 30 seconds interval & .203 & .037 & $.620^{*+*}$ & $.734^{* * * *}$ \\
\hline \multicolumn{5}{|l|}{ Young Adults } \\
\hline 1. Process-oriented object control skill & - & & & \\
\hline 2. Product-oriented object control skill & $.665^{\star * \star}$ & - & & \\
\hline 3. METS 6 seconds interval & $.602^{* * *}$ & $.428^{*}$ & - & \\
\hline 4. METS 12 seconds interval & $.648^{+* x+}$ & $.541^{* *}$ & $.830^{*+*}$ & - \\
\hline 5. METS 30 seconds interval & $.488^{* *}$ & $.371^{*}$ & $.568^{*+* x}$ & $.821^{* * *}$ \\
\hline
\end{tabular}

Note. ${ }^{*} p<.05,{ }^{* *} p<.01,{ }^{* * *} p<.001$. METS: metabolic equivalent of task

In a second step, multiple linear regressions, as well as RSA, were computed separately for children and young adults in the 6 second condition, the 12 second condition and the 30 second condition. Regarding the RSA, the only-x model (only the main effect of process-oriented object control skill competence) was the best fitting model for five conditions, while the null model (no meaningful estimator) represented the data best for the 30 second condition for children (for details, see Table 3 ). The full model did not fit the data best in any condition.

Table 3 - Model fit indices for the Response Surface Analysis regarding the effects of product- and process-oriented object control competence on METS for the 6 , 12 , and 30 second condition for children and young adults.

\begin{tabular}{|c|c|c|c|c|c|c|}
\hline Model & Best fitting model & $A I C$ & CFI & $p$ & adjusted $R^{2}$ & $p$ (full model) \\
\hline \multicolumn{7}{|l|}{ Children } \\
\hline 6 second condition & Only process-oriented bsc & 151.49 & .944 & .001 & .219 & .056 \\
\hline 12 second condition & Only process-oriented bsc & 138.44 & 1 & .034 & .087 & .335 \\
\hline 30 second condition & Null model & - & - & - & - & .286 \\
\hline \multicolumn{7}{|l|}{ Young Adults } \\
\hline 6 second condition & Only process-oriented bsc & 113.26 & .892 & $<.001$ & .341 & .004 \\
\hline 12 second condition & Only process-oriented bsc & 91.85 & 1 & .002 & .400 & .005 \\
\hline 30 second condition & Only process-oriented bsc & 64.97 & 1 & .005 & .213 & .137 \\
\hline
\end{tabular}

Thus, process-oriented differences in skill level mainly predicted metabolic expenditure in all three conditions for both children and young adults. As shown in Table 4 and Table 5, the analyses show that the explained variance of metabolic expenditure was lower for conditions with increased interval lengths for children (i.e., $21.9 \%, 8.7 \%, 0 \%$ for 6 , 12 and 30 second intervals, respectively) and partly for young adults (i.e., $36.2 \%, 42.0 \%$, $21.9 \%$ for 6,12 and 30 second intervals, respectively). Multiple linear regressions were included to illustrate the comparison between both analysis strategies and to illustrate the advantage of the RSA. Table 4 and 5 also show that the explained variance is higher for the 
more parsimonious RSA models compared to the multiple linear regression models. Furthermore, the baseline (intercept) of metabolic expenditure was also lower in conditions with increased interval rest duration for children and young adults. Simply, the longer the interval rest period the lower the baseline metabolic expenditure. Similarly, smaller effects of process-oriented skill level on metabolic expenditure were found in conditions with higher intervals for both children $(\beta=.488, .331, .000$ for 6,12 , and 30 seconds intervals, respectively) and young adults $(\beta=.602, .648, .488$ for 6,12 , and 30 second intervals, respectively; see also Figure 1 and 2).
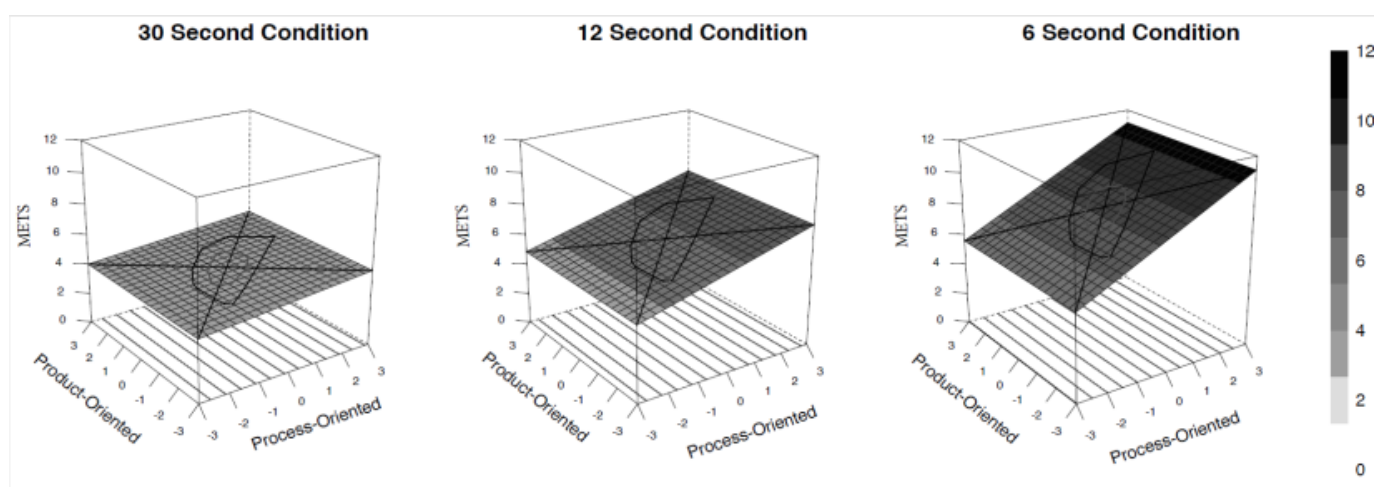

Figure 1. Response Surface Analysis illustrating the effects of product- and process-oriented object control skill competence on metabolic equivalents (METS) for the 6, 12, and 30 second condition for children.
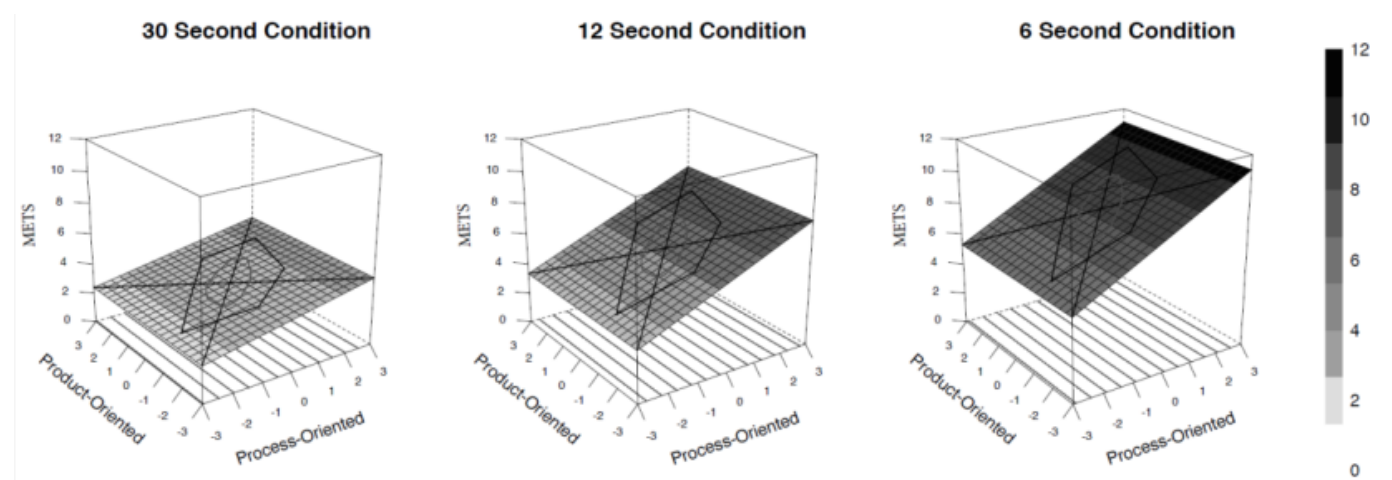

Figure 2. Response Surface Analysis illustrating the effects of product- and process-oriented object control skill competence on metabolic equivalents (METS) for the 6,12 , and 30 second condition for young adults. 
Brazilian Journal of Motor Behavior

\section{Research Article}

Table 4 - Results for the Response Surface Analysis regarding the effects of product- and process-oriented object control skill competence on METS for the 6 , 12 , and 30 second condition for children and a comparison with linear regressions.

\begin{tabular}{|c|c|c|c|c|c|c|c|c|c|c|c|c|}
\hline & \multicolumn{7}{|c|}{ Response Surface Analysis } & \multicolumn{5}{|c|}{$\begin{array}{c}\text { Linear } \\
\text { Regression }\end{array}$} \\
\hline & Estimate & $\begin{array}{c}\text { robust } \\
\text { SE }\end{array}$ & $\begin{array}{l}95 \% \mathrm{Cl} \\
\text { (lower) }\end{array}$ & $\begin{array}{l}95 \% \mathrm{Cl} \\
\text { (upper) }\end{array}$ & $\beta$ & $p$ & $\begin{array}{l}\text { adj. } \\
R^{2}\end{array}$ & Estimate & SE & $\beta$ & $p$ & $\begin{array}{l}\text { adj. } \\
R^{2}\end{array}$ \\
\hline \multicolumn{13}{|l|}{ Children } \\
\hline 6 second condition & & & & & & & .219 & & & & & .153 \\
\hline Intercept & 8.367 & 0.222 & 7.933 & 8.802 & $N A$ & $<.001$ & & 8.385 & 0.261 & $N A$ & $<.001$ & \\
\hline Process-oriented bsc & 0.931 & 0.211 & 0.030 & 0.136 & .488 & $<.001$ & & 1.035 & 0.667 & .362 & .129 & \\
\hline Product-oriented bsc & 0.000 & 0.000 & 0.000 & 0.000 & 0.000 & $N A$ & & 0.350 & 0.469 & .167 & .460 & \\
\hline Interaction & 0.000 & 0.000 & 0.000 & 0.000 & 0.000 & $N A$ & & -0.242 & 0.357 & -.109 & .501 & \\
\hline 12 second condition & & & & & & & .087 & & & & & .066 \\
\hline Intercept & 6.331 & 0.191 & 5.958 & 6.705 & NA & $<.001$ & & 6.284 & 0.218 & $N A$ & $<.001$ & \\
\hline Process-oriented bsc & 0.498 & 0.169 & 0.167 & 0.828 & .331 & .003 & & 0.600 & 0.559 & .263 & .289 & \\
\hline Product-oriented bsc & 0.000 & 0.000 & 0.000 & 0.000 & 0.000 & $N A$ & & 0.143 & 0.392 & .086 & .717 & \\
\hline Interaction & 0.000 & $N A$ & $N A$ & $N A$ & 0.000 & $N A$ & & 0.112 & 0.299 & .064 & .709 & \\
\hline 30 second condition & & & & & & & $N A$ & & & & & .008 \\
\hline Intercept & 4.460 & .112 & 4.239 & 4.680 & NA & $<.001$ & & 4.433 & 0.130 & $N A$ & $<.001$ & \\
\hline Process-oriented bsc & 0.000 & 0.000 & 0.000 & 0.000 & 0.000 & NA & & 0.514 & 0.333 & .390 & .252 & \\
\hline Product-oriented bsc & 0.000 & 0.000 & 0.000 & 0.000 & 0.000 & $N A$ & & -0.280 & 0.234 & -.290 & .242 & \\
\hline Interaction & 0.000 & $N A$ & $N A$ & $N A$ & 0.000 & $N A$ & & 0.082 & 0.178 & .08 & .174 & \\
\hline
\end{tabular}

Note. bsc = object control skill competence. The best fitting model from the Response Surface Analysis was the 'only-x' model (see Table 3). Therefore, we present the results from this model for the Response Surface Analysis. The 'only- $x$ ' model suppresses the main effect of product-oriented bsc and the interaction effect. METS: metabolic equivalent of task. 
Table 5 - Results for the Response Surface Analysis regarding the effects of product- and process-oriented object control skill competence on METS for the 6 , 12 , and 30 second condition for young adults and a comparison with linear regressions.

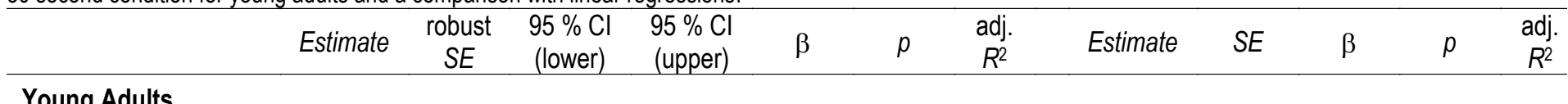

\section{Young Adults}

6 second condition

.362

\begin{tabular}{|c|c|c|c|c|c|c|c|c|c|c|}
\hline Intercept & 8.200 & .230 & 7.748 & 8.651 & $N A$ & $<.001$ & 8.241 & 0.297 & $N A$ & $<.001$ \\
\hline Process-oriented bsc & 0.974 & 0.179 & 0.624 & 1.324 & .602 & $<.001$ & 1.702 & 0.614 & .563 & .010 \\
\hline Product-oriented bsc & 0.000 & 0.000 & 0.000 & 0.000 & 0.000 & $N A$ & 0.128 & 0.434 & .061 & .771 \\
\hline Interaction & 0.000 & 0.000 & 0.000 & 0.000 & 0.000 & $N A$ & -0.133 & 0.599 & -.035 & 826 \\
\hline
\end{tabular}

12 second condition

.420

$\begin{array}{lrrrrrr}\text { Intercept } & 5.685 & 0.163 & 5.365 & 6.005 & N A & <.001 \\ \text { Process-oriented bsc } & 0.787 & 0.133 & 0.527 & 1.048 & .648 & <.001 \\ \text { Product-oriented bsc } & 0.000 & 0.000 & 0.000 & 0.000 & 0.000 & \text { NA } \\ \text { Interaction } & 0.000 & \text { NA } & \text { NA } & \text { NA } & 0.000 & \text { NA }\end{array}$

$\begin{array}{rrrr}5.753 & 0.208 & N A & <.001 \\ 1.150 & 0.430 & .507 & .012 \\ 0.342 & 0.304 & .219 & .270 \\ -0.197 & 0.420 & -.068 & .643\end{array}$

30 second condition

.239

$\begin{array}{lrrrrrr}\text { Intercept } & 3.393 & 0.108 & 3.181 & 3.605 & N A & <.001 \\ \text { Process-oriented bsc } & 0.340 & 0.090 & 0.165 & 0.516 & .488 & <.001 \\ \text { Product-oriented bsc } & 0.000 & 0.000 & 0.000 & 0.000 & 0.000 & \text { NA } \\ \text { Interaction } & 0.000 & \text { NA } & \text { NA } & \text { NA } & 0.000 & \text { NA }\end{array}$

$\begin{array}{rrrr}3.412 & 0.139 & N A & <.001 \\ 0.557 & 0.288 & .429 & .063 \\ 0.084 & 0.204 & .094 & .683 \\ -0.057 & 0.281 & -.034 & .842\end{array}$

Note. bsc $=$ object control skill competence. The best fitting model from the Response Surface Analysis was the 'only- $x$ ' model (see Table 3). Therefore, we present the results from this model for the Response Surface Analysis. The 'only- $x$ ' model suppresses the main effect of product-oriented bsc and the interaction effect. METS: metabolic equivalent of task.

\section{DISCUSSION}

The purpose of the current study was to determine relationships between processand product-oriented competence levels and METS during object control skill performance in children and young adults. Generally, results indicated that process- and product-oriented object control skill competence were positively associated with METS in children and young adults. Not surprisingly, young adults elicited higher process-oriented levels of skill and produced higher kicking and throwing speeds (product) than children produced. On average, boys and young men demonstrated higher process-oriented skill levels and produced higher kicking and throwing speeds (product) than girls and young women respectively. Boys and young men, on average, also produced significantly higher levels of EE (measured in METS, $p>$.001) across all conditions. One MET represents approximately 3.5 milliliters of oxygen consumed per kilogram of body weight per minute. In adults, one MET is the approximate equivalent to an individual's basal metabolic rate or the amount of energy consumed by the body while at rest. If an individual is producing movement at a rate of four METS this value 
is representative of $E E$ at a rate four times that of rest relative to the individual. As it relates to skilled performance, individuals of similar stature who produce varying levels of EE must also exhibit varying levels of effort or movement efficiency. Results from the current study indicate that individuals who perform movements with a higher level of skill as assessed by process-oriented measures elicit higher levels of EE. Simply, the more advanced the movement pattern, the more energy required to produce a movement skill.

The intermittent nature of repetitive motor skill performance provides a logical explanation for the relationship between $\mathrm{EE}$ and the rate of trial performance. As these results demonstrate, the faster the performance interval the higher the EE. The relationship of increased EE and decreased rest between trials was constant across all participants regardless of motor skill level. The current understanding of skill level and EE indicates that as skill level is increased EE is decreased.8,40 Efficiency of movement increases in continuous activities (e.g., walking, jogging, and running) as an individual becomes more skilled, eliciting a decrease in EE at a relative pace. ${ }^{8,40}$ Alternatively, higher levels of discrete skill performance (e.g., throwing and kicking) are demonstrated by higher accelerations and speeds of limbs throughout an improved range of motion and greater forces (i.e., eccentric loading, increased ground reaction forces) are required to decelerate limbs and the center of mass during the completion of each individual skill performance. ${ }^{41-44}$ The greater range of motion, increased neuromuscular demand and eccentric loading upon landing presumably increases metabolic energy demand. The current study suggests that highly skilled individuals demonstrate higher EE during object control skill performance. The strong association of process-oriented skill level illustrates that increased coordination and control results in higher levels of EE for both children and young adults. The results also suggest that this effect is more pronounced in more intense interval conditions.

Surprisingly, whilst product-oriented skill measures do not lack in significance or descriptive utility, they were not as closely associated with EE as their process-oriented counterpart. However, this does not diminish the role that product-oriented measurement should play in the future, rather, these results should amplify the importance of increasing motor skill performance level as a means of increasing PA. Thus, in the context of skilled performance, the promotion of advanced movement patterns performed with high effort should be emphasized with the aim of increasing health related fitness benefits associated with high levels of PA for all individuals regardless of stature. In view of the current findings, there is a clear need for more research into the interaction between product- and processoriented measures of motor competence. As noted by the study of Logan et al. (2017) comparing performance of process- and product-oriented assessments of motor skills across childhood, process- and product-oriented assessments, although related, provide different information with regard to competence levels. ${ }^{28}$ As each method provides one type of information, it is suggested to combine product- and process-oriented measures in skill assessment in order to have a more comprehensive understanding of $\mathrm{MC}$ and its effect on other health outcomes. ${ }^{2,28,45}$

A major strength of this study is the use of RSAs to illustrate the effects of processand product-oriented skill level on EE. The three-dimensional design of the RSA allows for easy and simultaneous interpretation regarding interactions of three variables (i.e., processoriented skill level, product-oriented skill level, and METS). The comprehensive assessment 
of $\mathrm{MC}$ in all forms is of increasing importance. Technological advances in motion capturing have led to a new focus on improving the efficiency and effectiveness of assessment in the field of motor development. ${ }^{45}$ For instance, Bisi et al. (2017) and Lander et al. (2020) have adopted wearable sensors to facilitate assessment of locomotor and object control skills included in the Test of Gross Motor Development. ${ }^{46,47}$ Concurrently, continued investigations into process- and product-oriented measurement are warranted to increase our understanding of $\mathrm{MC}$ and its effect on other health outcomes. The use of RSAs in the future may be beneficial to the analysis and interpretation of these multidimensional studies. In contrast, this study is not without limitations. For instance, there is a lack of understanding of the relative contribution of each skill toward the production of EE as well as the exclusion of striking from skill level assessment (i.e., due to the lack of a validated process assessment). However, all three skills are multi-joint ballistic skills with similar gross neuromuscular involvement and kinetic chain mechanisms. Thus; individual skill performance contributions relative to $\mathrm{EE}$ is expected to be similar. ${ }^{48}$

\section{CONCLUSION}

This study is a significant addition to the literature as it is the first study to explore the impact of skill levels and EE levels during object control skills using indirect calorimetry and process and product-oriented assessments in children and young adults. The importance of promoting activities that involve object control skills would seem beneficial to impact acute levels of health-enhancing PA in children and adolescence as there is strong evidence that the development of object control skills positively influences PA levels, ${ }^{49}$ multiple aspects of health-related physical fitness, ${ }^{11,50,51}$ and body weight status ${ }^{11,50,52-54}$ in youth. Information gleaned from this study provides evidence that the repetitive practice of object control skills can aid in the achievement of (acute) recommended health enhancing levels of EE (i.e., MVPA), as well as promote a foundation for skill development that promotes lifelong PA. Understanding the EE of all MC skills, both object control and locomotor, is critical to development of a foundation for future PA habits, health-related physical fitness and a healthy weight status. These data have the potential to significantly enhance our understanding of the usefulness of process- and product-oriented assessment tools to associate health enhancing levels of EE with skillfulness.

\section{REFERENCES}

1. Clark JE, Metcalfe JS. The mountain of motor development: A metaphor. Mot Dev Res Rev. 2002;2:163-190.

2. Robinson LE, Stodden DF, Barnett LM et al. Motor Competence and its Effect on Positive Developmental Trajectories of Health. Sport Med. 2015;45(9):1273-1284. doi:10.1007/s40279-015-0351-6

3. Sacko RS, Mclver K, Brian A, Stodden DF. New insight for activity intensity relativity, metabolic expenditure during object projection skill performance. J Sports Sci.

2018;36(21):2412-2418. doi:10.1080/02640414.2018.1459152 
4. Sacko, RS, Nesbitt D, Mclver K, Brian A, Bardid F, Stodden DF. Children's Metabolic Expenditure during Object Projection Skill Performance: New Insight for Activity Intensity Relativity. J Sport Sci. 2019;37(15):1755-1761. doi:10.1080/02640414.2019.1592801

5. Duncan M, Dobell A, Noon M et al. Calibration and cross validation of accelerometry for estimating sedentary behavior and physical activity involving fundamental movement skills in children aged 8-12 years. Sensors. 2020;20(10):2776. doi:10.3390/s20102776

6. Committee. PAGA. Physical Activity Guidelines Advisory Committee Scientific Report. Washington, DC; 2018.

7. Butte NF, Watson KB, Ridley K et al. A youth compendium of physical activities: Activity codes and metabolic intensities. Med Sci Sports Exerc. 2017;50(2):246. doi:10.1249/MSS.0000000000001430

8. Ainsworth BE, Haskell WL, Herrmann SD et al. Compendium of Physical Activities: a second update of codes and MET values. Med Sci Sports Exerc. 2011;43(8):1575-1581.

9. Jette M, Sidney K, Blümchen G. Metabolic equivalents (METS) in exercise testing, exercise prescription, and evaluation of functional capacity. Clin Cardiol. 1990;13(8):555565.

10. Pinnington HC, Wong P, Tay J, Green D, Dawson B. The level of accuracy and agreement in measures of FEO2, FECO2 and VE between the Cosmed K4b2 portable, respiratory gas analysis system and a metabolic cart. J Sci Med Sport. 2001;4(3):324-335.

11. Cattuzzo MT, dos Santos Henrique R, Ré AHN et al. Motor competence and health related physical fitness in youth: A systematic review. J Sci Med Sport. 2016;19(2):123-129.

12. Logan SW, Robinson LE, Getchell N, Webster EK, Liang L-Y, Golden D. Relationship between motor competence and physical activity: A systematic review. Res $Q$ Exerc Sport. 2014;85(S1):A14.

13. Utesch T, Bardid F, Büsch D, Strauss B. The relationship between motor competence and physical fitness from early childhood to early adulthood: A meta-analysis. Sport Med. 2019;49(4):541-551. doi:10.1007/s40279-019-01068-y.

14. Campbell BM, Stodden DF, Nixon MK. Lower extremity muscle activation during baseball pitching. J Strength Cond Res. 2010;24(4):964-971.

15. Duffield R, Dawson B, Pinnington H, Wong P. Accuracy and reliability of a Cosmed K4b 2 portable gas analysis system. J Sci Med Sport. 2004;7(1):11-22.

16. Escamilla RF, Andrews JR. Shoulder muscle recruitment patterns and related biomechanics during upper extremity sports. Sport Med. 2009;37(7):569-590.

17. Stodden DF, Langendorfer SJ, Fleisig GS, Andrews JR. Kinematic constraints associated with the acquisition of overarm throwing Part I: Step and trunk actions. Res Q Exerc Sport. 2006;77(4):417-427.

18. Stodden D, Langendorfer S, Fleisig G, Andrews J. Kinematic constraints associated with the acquisition of overarm throwing part II: upper extremity actions. Res Q Exerc Sport. 2006;77(4):428-436. 
19. Anderson FC, Pandy MG. A dynamic optimization solution for vertical jumping in three dimensions. Comput Methods Biomech Biomed Engin. 1999;2(3):201-231. doi:10.1080/10255849908907988

20. Sparrow WA, Newell KM. Metabolic energy expenditure and the regulation of movement economy. Psychol Bull Rev. 1998;5(2):173-196.

21. Girard O, Micallef J-P, Millet GP. Lower-limb activity during the power serve in tennis: effects of performance level. Med Sci Sports Exerc. 2005;37(6):1021-1029.

22. Holfelder B, Schott N. Relationship of fundamental movement skills and physical activity in children and adolescents: A systematic review. Psychol Sport Exerc. 2014;15(4):382-391.

23. Rodacki AL, Fowler NE, Bennett SJ. ertical jump coordination: fatigue effects. Med Sci Sports Exerc. 2002;37(1):105-116.

24. Stodden D, Langendorfer $S$, Roberton MA. The association between motor skill competence and physical fitness in young adults. Res Q Exerc Sport. 2009;80(2):223-229.

25. Pandy MG, Zajac FE. Optimal muscular coordination strategies for jumping. J Biomech. 1991;24(1):1-10.

26. Haywood KM, Getchell N. Lifespan Motor Development. 6th ed. Champaign, IL: Human Kinetics; 2020.

27. Roberton MA. Longitudinal evidence for developmental stages in the forceful overarm throw. J Hum Mov Stud. 1978;4(2):167-175.

28. Logan SW, Barnett LM, Goodway JD, Stodden DF. Comparison of performance on process-and product-oriented assessments of fundamental motor skills across childhood. $J$ Sports Sci. 2017;35(7):634* - 641.

29. Valentini N, Getchell N, Logan SW et al. Exploring associations between motor skill assessments in children with, without, and at-risk for developmental coordination disorder. J Mot Learn Dev. 2015;3(1):39-52.

30. Logan SW, Robinson LE, Rudisill ME, Wadsworth D, Morera M. The comparison of schoolage children's performance on two motor assessments: The Test of Gross Motor Development and the Movement Assessment Battery for Children. Phys Educ Sport Pedagog. 2014;19(1):48-59. doi:10.1080/17408989.2012.726979

31. Roberton MA, Konczak J. Predicting children's overarm throw ball velocities from their developmental levels in throwing. Res Q Exerc Sport. 2001;72(2):91-103.

32. Melby C, Scholl C, Edwards G, Bullough R. Effect of acute resistance exercise on postexercise energy expenditure and resting metabolic rate. J Appl Physiol. 1993;75(4):1847-1853.

33. Sacko RS, Utesch T, Cordovil R et al. Developmental Sequences for Forceful Kicking. Eur Phys Educ Rev. 2020;1(19). doi:10.1177/1356336X20962134

34. Safrit MJ, Wook T. Introduction to Measurement in Physical Education and Exercise Science. (3rd ed.). St Louis: Mosby-Year Book; 1995. 
35. Stodden DF, Gao Z, Goodway JD, Langendorfer SJ. Dynamic relationships between motor skill competence and health-related fitness in youth. Pediatr Exerc Sci. 2014;26(3):237241.

36. Schönbrodt FD. RSA: An R package for response surface analysis. 2017.

37. Bozdogan H. Model selection and Akaike's Information Criterion (AIC): The general theory and its analytical extensions. Psychometrika. 1987;52(3):345-370.

38. Bollen KA, Jackman RW. Regression Diagnostics: An Expository Treatment of Outliers and Influential Cases. Sociol Methods Res. 1985;13(4):510-542. doi:10.1177/0049124185013004004

39. R Core Team. R Core Team (2017). R: A language and environment for statistical computing. R Found Stat Comput. 2017.

40. Butte NF, Watson KB, Ridley K et al. A youth compendium of physical activities: Activity codes and metabolic intensities. Med Sci Sports Exerc. 2017;50(2):246.

41. Stodden DF, Langendorfer SJ, Fleisig GS, Andrews JR. Kinematic constraints associated with the acquisition of overarm throwing part I: Step and trunk actions. Res Q Exerc Sport. 2006;77(4):417.

42. Stodden DF, Langendorfer SJ, Fleisig GS, Andrews JR. Kinematic constraints associated with the acquisition of overarm throwing Part II: Upper extremity actions. Res Q Exerc Sport. 2006;77(4):428-436.

43. Sacko RS, Brazendale K, Brian A, et al. Comparison of Indirect Calorimetry- and Accelerometry-Based Energy Expenditure during Object Project Skill Performance. Meas Phys Educ Exerc Sci. 2018;00(00):1-11. doi:10.1080/1091367X.2018.1554578

44. Orloff H, Sumida B, Chow J, Habibi L, Fujino A, Kramer B. Ground reaction forces and kinematics of plant leg position during instep kicking in male and female collegiate soccer players. Sport Biomech. 2008;7(2):238-247.

45. Bardid F, Vannozzi G, Logan SW, Hardy LL, Barnett LM. A hitchhiker's guide to assessing young people's motor competence: Deciding what method to use. J Sci Med Sport. 2019;22(3):311-318. doi:doi.org/10.1016/j.jsams.2018.08.007

46. Bisi MC, Pacini Panebianco G, Polman R, Stagni R. Objective assessment of movement competence in children using wearable sensors: An instrumented version of the TGMD-2 locomotor subtest. Gait Posture. 2017;(56):42-48.

doi:doi.org/10.1016/j.gaitpost.2017.04.025

47. Lander N, Nahavandi D, Mohamed S, Essiet I, Barnett LM. Bringing objectivity to motor skill assessment in children. J Sports Sci. doi:doi.org/10.1080/02640414.2020.1747743

48. Langendorfer S, Roberton MA, Stodden D. 9 Biomechanical Aspects of the Development of Object Projection Skills. In: Pediatric Biomechanics and Motor Control: Theory and Application; 2011:180-206. 
49. Lima RA, Pfeiffer KA, Bugge A, Møller NC, Andersen LB, Stodden DF. Motor competence and cardiorespiratory fitness have greater influence on body fatness than physical activity across time. Scand J Med Sci Sport. 2017;1(10).

50. Lima RA, Pfeiffer K, Larsen LR et al. Physical activity and motor competence present a positive reciprocal longitudinal relationship across childhood and early adolescence. $J$ Phys Act Heal. 2017;14(6):440-447.

51. Rodrigues LP, Stodden DF, Lopes VP. Developmental pathways of change in fitness and motor competence are related to overweight and obesity status at the end of primary school. J Sci Med Sport. 2016;19(1):87-92.

52. D'Hondt E, Deforche B, Gentier I et al. A longitudinal study of gross motor coordination and weight status in children. Obesity. 2014;22(6):1505-1511.

53. Lopes VP, Stodden DF, Rodrigues LP. Weight status is associated with cross-sectional trajectories of motor co-ordination across childhood. Child Care Health Dev. 2014;40(6):891-899.

54. Martins D, Maia J, Seabra A. Correlates of changes in BMl of children from the Azores islands. Int J Obes. 2010;34(10):1487.

\section{ACKNOWLEDGEMENTS}

The Authors would like to acknowledge Moritz Eggelbusch for his contributions in data collection and analysis that aided in the creation of this manuscript.

Citation: Sacko RS, Utesch T, Bardid F, Stodden DF. The impact of motor competence on energy expenditure during object control skill performance in children and young adults. BJMB. 2021. 15(2): 91-106.

Editors: Dr Fabio Augusto Barbieri - São Paulo State University (UNESP), Bauru, SP, Brazil; Dr José Angelo Barela São Paulo State University (UNESP), Rio Claro, SP, Brazil; Dr Natalia Madalena Rinaldi - Federal University of Espírito Santo (UFES), Vitória, ES, Brazil.

Copyright:@ 2021 Sacko, Utesch, Bardid and Stodden and BJMB. This is an open-access article distributed under the terms of the Creative Commons Attribution-Non Commercial-No Derivatives 4.0 International License which permits unrestricted use, distribution, and reproduction in any medium, provided the original author and source are credited. Funding: This research did not receive any specific grant from funding agencies in the public, commercial, or not-forprofit sectors.

Competing interests: The authors have declared that no competing interests exist.

DOI: https://doi.org/10.20338/bjmb.v15i2.208 